\title{
Grundtvig-litteratur $195^{8}$.
}

En bibliografisk oversigt ved Steen Johansen.

\section{Bibliografi.}

Steen Johansen: Grundtvig-litteratur 1956. - Gr.-Studier 1958, II I-I I 9.

Registrant over N.F.S. Grundtvigs papirer. Udgivet af Grundtvig-Selskabet af 8. september 1947 og Det Danske Sprog- og Litteratur-Selskab. IV-IX. I958. - (Bd. IV: fasc. I 29-I 4 I.30; V: fasc. I4I.3 I-I 44; VI: fasc. I45-I49.40; VII: fasc. I49.41-I64; VIII: fasc. 165-188; IX: fasc. I89-20I).

Knud Eyvin Bugge: Grundtvig-samlingen på Instituttet for Dansk Kirkehistorie. - Gr.-Studier 1958, 84-98. - Heri også meddelt flere (hidtil utrykte) dedikationer skrevet af Gr., oplysninger om korrektureksemplarer og andre bøger med Gr.s egenhændige rettelser eller tilføjelser, oplysninger om optryk (enkelttryk) af digte af Gr. (Enkelt-optryk af digte registreres principielt ikke i Gr.-bibliografien, undtagen hvis Gr. har ændret i teksten, jf. nævnte værk III, s. 2, hvor dette måske ikke er sagt tydeligt nok).

Ernst J. Borup: Ti aar i Vartov. - Vartovbogen 1958, I I9-140. - Heri også (s. 135) om Gr.-biblioteket i Vartov.

\section{Tekstudgivelser, optryk, overscettelser.}

Grundtvigs tale ved det udvidede landemode i juli 1812. Udgivet af Knud Eyvin Bugge. - Gr.-Studier 1958, 51-73. - Heri er s. 52-68 aftrykt Gr.s tale ved nævnte landemode.

Et af Grundtvig paa tysk skrevet tilbageblik paa sig selv fra vinteren 1813-14. Med indledning, noter og efterskrift ved Steen Johansen. - Gr.-Studier 1958. 74-83. (Dateringen januar $18{ }_{13}$ anf. st. s. 82 er en fejl for januar 1814).

Diverse dedikationer etc., se Knud Eyvin Bugge i gruppe I ovenfor.

\section{Samlede fremstillinger, karakteristikker. Den moderne Gr.-forskning $i$ alm. Gr.s indflydelse udenfor Danmark.}

Videnskaben for alvor i gang med Gr. - Kr. Dagbl. 8. sept. 1958. (Artikel, undertegnet: $b a k$.). - Heri om Gr.-forskningen nu, om Gr.-Selskabet, Gr.-registranten m. m.

Jorgen Elbek: Gr. og vi. - Information 8. sept. 1958. - I anledning af Gr.s I 75 -årsdag. 
Svend H. Henriksen: Gr. i samtidiges bedømmelse. - Dannevirke 2. sept. $195^{8}$.

Ingemar Ingers: Gr. och Sverige. Några försök att göra Danmarks störste präst känd i vårt land. - Lunds Dagblad I4. jan. 1958.

Ingemar Ingers: Hur Gr. blev känd i Sverige. - Lunds Dagblad 20., 28. og 30. jan. 1958. - Om disse 4 artikler af Ingers, se Fr. Schroder: Hvordan Gr. blev kendt i Sverige. - Højskolebl. 21. marts 1958.

F. J. Billeskov Jansen: Danmarks Digtekunst. Tredie Bog. Romantik og Romantisme. 1958 (423 s.). - Heri Gr.s digtning behandlet, især s. 49-55,

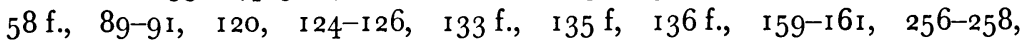
$334 \mathrm{f} ., 344 \mathrm{f} ., 346-349,355-362$.

Hermann Pongs: Das kleine Lexikon der Weltliteratur. Stuttgart 1958. (3. Aufl.). Heri (sp. 647) en mindre artikel om Gr.

Kaj Thaning: 175 aar. - Højskolebl. 5. sept. 1958. - (I anledn. af I75-året for Gr.s fødsel). - Heri dels om grundtvigianismen i nutiden, dels og især om den moderne Gr.-forskning og den deraf fremgåede reviderede opfattelse af Gr. - Heraf et større citat i Kr. Dagbl. 8. sept. $1958 \mathrm{~m}$. overskriften: Gr.s udviklingshistorie.

\section{Specialia vedrorende Gr.s liv og forfatterskab.}

a. Slacgt; forhold til slaegtninge.

Hans Egede Glahn: Poul Egede Glahn. Præsten, der viede Kong Christian IX og Dronning Louise. - Personalhist. Tidsskr. 1958, 38-45. - I denne afh. om Gr.s svoger også personalia om Gr. selv.

Optrykket i Dansk Kirketid. I958 af Chr. Mikkelsens afh. om Gr.s mødrene slægt, se årsbibliografien i Gr.-Studier 1959, I1 7 .

b. Studier etc. overvejende af biografisk indhold.

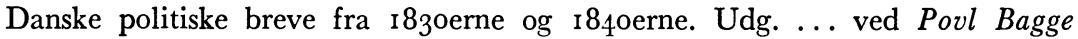
og Povl Engelstoft (og for sidste binds vedkommende også: Johs. Lomholt-Thomsen) I-IV, 1945-58. - Heri ikke få samtidiges udtalelser om og bedømmelser af Gr. i denne periode, jf. værkets register.

N.J.Gregersen: Gr. og Norge. - Vejle Amts Folkeblad 7.nov. 1958. Om Gr.s tanker om Norden og især Norge. Overvejende biografisk.

Finn Hasselager: Fru Constances bibel. - Berl. Tid. 24. aug. 1958.

Ingemar Ingers: Gr. och Udby prästgård. - Skånska Dagbladet 21. nov. 1958. Carl Th. Jørgensen: En bette grundtvigianer - eller måske ikke engang det?

- Kr. Dagbl. 8. sept. 1958. - Om et besøg i Udby og om Gr. og Udby.

Thorvald Laursen: Friskolesangen. - Antvorskov Højskole gennem 50 år. 1908-1958 (Årsskrift 1958), 69-70. - Om oprettelsen af Dronningens Asylskole I84 I og Gr.s sang ved indvielsen.

Thorvald Laursen: Ved Gr.s grav i Køge Aas. - Fyns Tid. II. marts 1958. - Et næsten uændret optryk af sammes artikel i Vejle Amts Folkeblad I 2. nov. I956, jf. Gr.-Stud. I958, I 2. 
Jens A. Nielsen: Snorre, Gr., og Gisselfeld. - Folketidende, RingstedSorø-Haslev I I. sept. 1958. - Om det på Gisselfeld bevarede eks. af Gr.s Snorre-oversættelse m. 2 egenhændigt af Gr. indskrevne digte. Det oplyses også, at et eks. af Saxo m. et egenhændigt digt af Gr. befinder sig på Brattingborg.

Jens A. Nielsens afh. »En fødselsdag på Gisselfeld ...« blev ved en fejltagelse registreret i Gr.-Studier 1959, II8 og med trykfejlen 1957 for I958 (anf. st. lin. Io f. o.). Afh. hører til i nærv. oversigt.

C.S. Nygaard: De grundtvigske retninger. - Ringkøbing Amts Dagbl. I5.-I6. jan. 1958. - En biogr. afh. om de skelsættende årstal i Gr.s liv. Titlen er således lidt misvisende.

Om Gr. og Rasmus Sørensen, se Knud Banning i gruppe IV n i det flg.

I958 var I50-året for søtræfningen ved Sjællands Odde 22. marts I808. Adskillige artikler og afhandlinger fremkom, hvori også Gr.s indskrift på den bekendte mindestøtte omtaltes, eller hvor Gr.s forhold til Willemoes fremstilledes. Se fortegnelsen i Avis Kronik Index 1958, 98 og 99. - Flg. artikler, der især berører Gr., kan nævnes: Niels Friis: »De snekker mødtes i kveld paa hav -«. Fyns Stiftstid. 21. marts 1958; Birger Isaksen: Gr. og Willemoes. Fyns Tid. I7. jan. 1958; Børge Petri: Mindesmærkerne på Odden kirkegård. Roskilde Stiftsblad. Marts 1958 (9. årg. nr. 3), 40-42; Børge Ørsted: Et romantisk møde. Berl. Aftenavis 21. marts 1958 .

\section{c. Littercert ell. personligt forhold til enkeltpersoner eller disses forhold til $\mathrm{Gr}$.}

K. Steffensen: Et træk i Kamma Rahbeks billede. - Kr. Dagbl. 19. og 20. marts 1958. - Heri om K. R., hendes bekendtskab med Gr. og forsvar for Gr.s kristendom.

Om Gr. og Willemoes, se forrige gruppe (IV b slutn.).

\section{d. Teologiske, filosofiske og psykologiske sporgsmål vedr. Gr.s forfatterskab.}

Michael Grell: Gr.s syn paa ordet. - Dansk Kirketid. 20. og 27. juli 1958. Villiam Gronbaek: Religionspsykologi. Forskere og forskning. I958 (317 s.). - Heri s. $28 \mathrm{I}-282$ om Gr.s opfattelse af den sjælelige forskel mellem mand og kvinde. Også andre steder om Gr., jf. bogens register.

Erik Heinemeier: Vi er alle præster. - Julebogen. Udg. af Kirk. Samfund af 1898. 1958, 86-96. - Heri også om Gr.s kirkesyn.

$H-n$ : Gr.-Kierkegaard. Professor Lindhardts opfattelse af Gr. - En imødegåelse af sognepræst Kaj Thaning. - Højskolebl. 24. jan. 1958. - En artikel baseret på 2 afhandlinger, henholdsvis af P. G. Lindhardt og af Kaj Thaning i Dansk Udsyn nr. 3 og 7, 1957, jf. Gr.-Studier i959, i I9.

Johannes Knudsen: Revelation and Man According to N.F.S.Gr. - The Lutheran Quarterly. Vol. X. nr. 3, aug. 1958, 21 7-225.

P. G. Lindhardt: Helvedesstrategi. 1958 (I12 s.). - Heri s. 40 ff. om Gr.s opfattelse af »helvede«. Også, s. 73 ff., om grundtvigianismen i Norge i det I9. årh. 
P. G. Lindhardt: Helvedesstrategi. - Jyllandsposten 8. juni 1958. - Heri også om grundtvigianernes opfattelse af livet efter døden.

N. Jul Petersen: Religiøsitet eller kristendom. - Dansk Kirketid. 2. og 9. febr. I958. - Heri også om Gr.s kristendom.

Udførligt referat af tale af biskop Gudmund Schiøler over emnet: hvad er grundtvigianismen og hvad vil den? - Folketidende. Ringsted-SorøHaslev 5. sept. I958. Den anførte emnetitel oplyst i nævnte blad. I virkeligheden kom foredraget til at handle om Gr.s syn på bibelen. - Et større citat herfra i Kr. Dagbl. 8. sept. I958, overskrift: Gr. og bibelen.

Fl. Lygaard Sørensen: Gr. og bispeembedet. - Dansk Kirketid. I 7. aug. I958.

\section{e. Litterære eller filologiske behandlinger \\ af Gr.s forfatterskab bortset fra salmerne.}

Sune Andresen: Lidt om mytologisk historiesyn. - Engelsholm Højskole. Årsskrift 1958, 38-42. - Heri også om Gr.s historiesyn.

Karl Clausen: Dansk folkesang gennem 150 år (Statsradiofoniens grundbøger). (338 s.). - Heri også om Gr. og folkevisen, om oprettelsen af »Danske Samfund « og om denne forenings visebøger m. sange af Gr., om Gr. som forfatter af folkelige og nationale sange, Boisens visebog, højskolesangbogens opståen osv.

Uffe Hansen: Den levende Røst. - Gr.-Studier 1958, 36-46. - Om Gr.s »Den levende Røst « I 863.

Henry Kaiser: Omkring en paaskelilje. - Vendsyssel Tid. 6. apr. I958. Om »Paaske-Lilien «.

Dansk-amerikaner skriver disputats om Gr. - Interview i Kr. Dagbl. 7. febr. I958 med professor P. Merville Larson. I dette interview også om Gr. som taler. - Den omtalte disputats var Paul Merville Larson: A Rhetorical Study of Bishop Nicholas Frederick Severin Grundtvig. A Dissertation ... for the degree Doctor of Philosophy. Evanston, Illinois. 1942 (Ca. 365 maskinskrevne sider). Findes som mikrofilm i Det Kgl. Bibliotek, $\mathrm{Kbh}$.

Svend Aage Nielsen, se gruppe f. 2 i det flg.

Paul V.Rubow: Gr.s Billedsprog. - Tr. i sammes bog: Herman Bang og flere kritiske Studier, I958, 25-29. - Udgør P. V. R.s opposition ved H. Toldbergs disputats 1950. Artiklen tidligere trykt, se Gr.-Stud. I952, I03.

Peter Skautrup: Krone paa Baar'. - Gr.-Studier I958, 50. - Supplement til kommentar til »De Levendes Land« ved P. Skautrup i Gr.-Studier 1956, 2 I-39.

Steffen Steffensen: Gr. und die deutsche Romantik. - Beiträge zur deutschen und nordischen Literatur. Festgabe für Leopold Magon zum 70. Geburtstag 3. April 1957. Berlin 1958, 282-290.

Helge Toldberg: Zur Holsteinischen Reimchronik. - Samme bog 392-405. Heri også kortfattet om Gr.s Rimkrønikestudier. 


\section{f. Gr.s salmer.}

I.

Om flere salmer eller om salmerne i almindelighed.

Adolph Andersen: Glimt fra Gr.s jul og hans juledigtning. - Vejle Amts Folkebl. 22. dec. I958. - Om Gr.s julesalmer, men også biografisk: om julen i Gr.s barndomshjem og senere i hans eget hjem.

Jorgen Elbek: Dateringer. - Gr.-Studier 1958, 47-49. - Heri meddelt omdateringer af ${ }^{4} 4$ salmer af $\mathrm{Gr}$.

Aage Jensen: Vore pinse-salmer. - Aarhus Amtstid. 24. maj 1958. - Om Gr. som pinsens salmedigter.

Paul Nedergaard: Tonen fra himlen -. Når julen synges ind i Nordens kirker. - Kr. Dagbl. 23. dec. 1958. - Heri også kortfattet om Gr.s julesalmer.

2.

Enkelte salmer.

Uffe Hansen: Nyoptaget Gr.-salme. - Dag. Nyh. 4. maj i958. - Om salmen »Vor Herre! til Dig maa jeg tye«.

Svend Aage Nielsen: Paaskeblomsten og vor kirke i dag. - Sorø Amtstid. 2. april 1958. - Om salmen »Paaskeblomst! hvad vil du her?« (og om $»$ Paaske-Lilien «).

Jacob Paludan: Omkring »Den signede Dag -«. - Digt og Læser. En Række Tolkninger af danske Digte under Redaktion af Volmer Dissing, 1958, 66-76 (med salmen aftrykt s. 74-76). Optrykt i sammes »Røgringe« ( 1959 ), I00-I08 (salmen ikke optrykt).

g-m. Gr. og England, Gr. som politiker, Gr. og det folkelige, det menneskelige, folkehojskolen, Norden, skolesporgsmål, sociale sporgsmål.

(Udvalg).

O. Helstrup Andersen: Mennesket i centrum. - Skanderup Ungdomsskole. Årsskrift 1958, 35-39. - Heri også om Gr. og det menneskelige.

Einar Arne: Folkehøgskulen si oppgåve i dag. - Kirke og Kultur, 1958, $416-428$.

Gustaf Bengtsson: Der er sandhed i myten. - Lollands Højskole I958, 5-12. - Heri også om Gr.

Jørgen Bukdahls tale ved indvielsen af Snoghøj til en »nordisk-europæisk folkehøjskole« 3. aug. 1958: referat og citater i Højskolebl. 15. aug. 1958. - Heri om Gr.s og Kolds oplysningsbegreb.

Th. B. Enevoldsen: Om højskolen. - Fyns Venstreblad I I. jan. 1958.

Poul Engberg: Nordisk-europæisk folkehøjskole på Snoghøj. - Julebogen. Udg. af Kirk. Samfund af r898, 1958, 43-55. - Heri også om Gr.s folkelige syn og tanker om Norden.

Poul Engberg: Opgaven på Snoghøj. - Købmandshvile. Folkehøjskolen for unge handelsmedhjælpere. Årsskrift 1958, 2 I-26. 
Poul Engberg: Sydslesvig og Norden. - Flensborg Avis 15. juli 1958. - Om den nord. folkehøjskole på Snoghøj.

Arne Frandsen: Folkehøjskole - faghøjskole. - Ubberup Højskoles Aarsskrift 1958, I6-24.

J.Hattinger-Jacobsen: Den frie skole - folkelighedsbetragtet. - Køng Folkehøjskoles Arsskrift 1958, I5-19.

Kr. B. Hillgaard: Skolen for Livet. - Dansk Kirketid. I958, I9. og 26. okt. 1958. - Om Gr.s livsoplysning.

Harald Jensen: Gr.s højskoletanke. - Ringkøbing Amts Dagbl. 8. sept. 1958.

Vedrørende dr. Laacks påstand (i Tinglev i apr. 1958) om, at højskoletanken oprindelig er overført fra Tyskland, se Højskolebl. 2. maj 1958. - Jf. også Chr. Petersen ndf.

William Michelsen: Gr. og skolereformen. - Information 12. maj 1958.

Chr. Petersen: Hvor kom højskoletanken fra? - Højskolebl. 23. maj 1958.

Johs. Rosendahl: Højskolen og historien. - Dansk Udsyn I958, 208-217, $28 \mathrm{I}-298$.

Rolf Schroder: Med Gr. til Mysore. - Demokraten I4. juni 1958. - Om den i Mysore i Indien oprettede højskole efter dansk mønster.

Fr. Schroder: Det store sker tyst. - Højskolebl. 28. marts 1958. - Heri om de første højskolemænd (»Lille Theologicum«).

Doktordisputats paa Sorbonne om Gr. og sagaerne. Fransk forfatterinde, madame E.Simon-Volboudt, forbereder i disse aar doktorafhandling om den idéhistoriske baggrund for folkehøjskolen. - Artikel om og interview med førnævinte i Information 22.-23. marts 1958 .

J.P.Trap: Danmark ${ }^{5}$ I, I (1958), 284 ff.: om folkehøjskolen.

Kjeld Winding: Danmarks Historie. 1958. (366 s.). (Statsradiofoniens grundbøger). - Heri et kapitel m. titlen: Højskoler og andelsbevægelse (s. $237 \mathrm{ff}$.), hvori også (s. 237-240) om folkehøjskolen, Gr. og Kold.

(anonym): Møde med Gr. i dag. - Højskolebl. 5. sept. I958. - En ung højskolelærer udtaler sig om Gr.; består hovedsagelig af citater af skrifter af $\mathrm{Gr}$.

\section{n. Grundtvigianismen (kirkehistorisk).}

(Udvalg).

Knud Banning: En Landsbylærer. Skolelærer Rasmus Sørensens ungdom og lærergerning I799-I844. Kirkehistoriske Studier. II. række nr. 3. 1958. ( 1 3 I s.). - Heri også om R. S.s forhold til Gr.

Knud Banning: Degnekristne. En Almuerejsning. En Studie over den gudelige Vækkelse paa Sydvestsjælland med særligt Henblik paa Skolelærer Rasmus Sørensens Virke. Kirkehistoriske Studier. II. række nr. 4. 1958. (357 s.). - Disputats. Forsvaret fandt sted I4. okt. I958. - Heri også om R. S.s personlige forhold til Gr. og hans stilling til Gr.s skole- og kirketanker. - Bannings 2 bøger bl. a. anmeldt af Knud Eyvin Bugge i Gr.-Studier 1959, 103-108. - »Degnekristne« anm. af P. G. Lindhardt i Højskolebl. 24. okt. I958. 
V. Baunbæek: Det grundtvigske præstekonvent i København. Begyndelsen til Kirkeligt Samfund. - Vartovbogen 1958, ro I-r I8.

Vagn Christensen: Lægmanden og kirken. (Foredrag). - Studenterkredsen, 26. årg. nr. 2 (dec. 1958), I7-23. - Om grundtvigianismen. - (I samme årgang af $\gg$ Studenterkredsen $\ll$ referater af adskillige foredrag med grundtvigianismen som emne).

Axel Hjeresen: Frihed og saa videre. - Dag. Nyh. 27. juli 1958. - Et angreb på de grundtvigianske frihedsbegreber og på grundtvigianismen. - Hertil Fr. Schroder: To kirkesyn. Holbæk Amtstid. 31. juli 1958 og samme: Grundtvigianernes synderegister. Højskolebl. I5. aug. 1958.

Den danske Kirkes Historie. Under Redaktion af Hal Koch og Bjørn Kornerup $\dagger$. VII. Tiden I849-190 I af P. G. Lindhardt. (376 s.). - Heri udførligt om grundtvigianismen $\mathrm{i}$ århundredets anden halvdei. - Hertil bl. a. Kaj Thaning: Lindhardts historieskrivning. Højskolebl. 28. nov. 1958.

E. Brandt Nielsen: De frie grundtvigske menigheders fremtid. - Dansk Kirketid. 2 I. sept. 1958.

Erik B. Nissen: Har de kirkelige retninger ødelagt folkekirken? - Sorø Amtstid. I6. sept. 1958.

To højkirkemænd. Brevvexling mellem bisperne H. Stein og J. Swane. Ved P. G. Lindhardt og Jørgen Swane $\dagger$. Skrifter udgivet af Jysk Selskab for Historie, Sprog og Litteratur 4. 1958. (504 s.). - Heri kan ved registerets hjælp findes frem til udtalelser om grundtvigianismen og grundtvigianere. - Hertil Peter Riemann: En højkirkelig brevveksling. Højskolebl. Io. okt. I 958 .

Kaj Thaning: Gr. og bispevalget. - Fyns Tid. I I. febr. 1958. - I anledn. af valg af en biskop over Fyns stift: om kirkens situation i dag, hvor »retning « eller »linie« tæller mindre end de personlige egenskaber. - Hertil J. Fog: Gr., Tidehverv, bispevalg. Fyns Tid. 25. febr. 1958. - Hertil Kaj Thaning: »Tidehvervsgrundtvigianere«. Smst. I. marts I958. - Hertil J. Fog: Grundtvigianere og tidehvervsgrundtvigianere. Smst. 4. marts 1958.

A. Pontoppidan Thyssen: »Kirkeligt Samfunds« Tilblivelse. Bidrag til Belysning af den gammelgrundtvigske Retning. II. - Kirkehist. Samlinger 7. række III, andet Hefte (1958), 285-363. - En fortsættelse af den smst. I954, I7 I ff. trykte afhandling »Det grundtvigske Møde i Middelfart I891 og dets Forudsætninger《 (jf. Gr.-Studier 1956, I12). - Hertil Fr. Schrøder: Kirkeligt Samfunds tilblivelse. Højskolebl. 2. maj 1958.

A. Pontoppidan Thyssen: Den første nygrundtvigianer. Lidt om Bjørnson og grundtvigianismen. - Dansk Kirkeliv I958, 64-81.

A.Pontoppidan Thyssen: Den nygrundtvigske Bevægelse med særligt Henblik paa den Borupske Kreds. I. 1870-1887. 1958. (495 s.). - Disputats. Forsvaret fandt sted 27. marts 1958. - Af de særdeles talrige anmeldelser af og artikler om dette værk skal her blot nævnes følgende (alfabetisk efter forff.):

Gustav Albeck i Gr.-Studier 1958, 99-103; Rudolph Arendt i Dansk Kirketid. I. juni 1958; Jorgen Bukdahl: Det forjættede land. Omkring P. Th.s disputats. Kr. Dagbl. 27. marts 1958; samme: Det forjættede land. Omkring P. Th.s disputats. Dansk Udsyn 1958, I64-182 (Denne anmel- 
delse fremkaldte en art. af Fr. Schrøder i Højskolebl. 4. juli 1958). Jorgen Bukdahl: Naar de døde vaagner -. Omkring en dansk disputats. Kirke og Kultur 1958, 547-560; Peder Bukh: Tanker omkring den såkaldte nygrundtvigianisme. Dansk Kirketid. 3., I7. og 24. aug. 1958; Hal Koch: Grundtvigsk nederlag. Da den folkelige dannelse blev kvalt af den akademiske eksamenskultur. Politiken 27. marts 1958. (Denne anmeldelse gav anledning til bl. a. følgende: Sune Andresen: Tanker bag tidens lammeskyer. Julebogen. Udg. af Kirk. Samfund af I898, 1958, I07-120; Chr. Petersen: Det grundtvigske nederlag. Højskolebl. 9. maj 1958; Holger Schrøder: Grundtvigsk nederlag. Højskolebl. I I. apr. 1958). Søren Holm: Nygrundtvigianismen. Berl. Tid. 27. marts 1958; S. J. Led: Ny grundtvigianisme. Aalborg Amtstid. 2. juli 1958; $P$. G. Lindhardt i Jyske Samlinger 1957-58 (1958), 317-323; Erik B. Nissen: Omkring »Den nygrundtvigske Bevægelse«. Højskolebl. 25. apr. 1958; Fr. Schrøder i Højskolebl. 4. apr. I958 (kort referat af disputatshandlingen) og 23. maj (anmeldelse); Carl Trock i Præsteforeningens Blad 18. apr. 1958. - Et brudstykke af disputatsen aftryktes i Højskolebl. 4. apr. 1958.

Hilmer Wentz: Kyrklig skandinavism. - Skånska Dagbladet 27.jan. I958. - Også om grundtvigianismen.

o. Gr. og missionen.

p. Grundtvigianere.

(Udvalg).

Frode Aagaard: Budstikke-Bojsen. - Fyns Tid. 19. marts 1958.

Frode Aagaard: Jacob Chr. Lindberg. - Vartovbogen 1958, 20-36.

Erik Appel: Sofus Høgsbro som aktiv højskolemand. Rødding Højskole 1850-62. - Askov Lærlinge. Arsskrift I958 (Jan. 1959), 44-56. - Også i Dansk Udsyn 1959, 44-56.

Kaj Baagø: Magister Jacob Christian Lindberg. Studier over den grundtvigske bevægelsens første kampe. 1958. (380 s.) - Disputats. Forsvaret fandt sted 22. nov. 1958. - Anmeldt bl. a. af Kaj Thaning i Højskolebl. 5. dec. 1958. Hertil imødegåelse af $K a j$ Baagø smst. I959 nr. I, endvidere et indlæg af Arne Brandt Pedersen smst. $1959 \mathrm{nr} .2$, Kaj Thanings svar ligeledes i nr. 2, hvorefter Baagøs gensvar smst. nr. 5, 1959 .

Uffe Hansen: Af salmesangens historie XIV. - Dansk Kirketid. 21. dec. 1958. - Bl. a. om flere grundtvigianere som salmedigtere (C. J. Brandt, P. G. Kierkegaard, Vilh. Birkedal, C. Hostrup o. fl.).

Kr. Toftdahl Moller: Et Ioo aars minde. Ioo aar siden kultusministeriet godkendte Christen Kolds skole. - Holbæk Amtstid. 23. sept. I958.

$K r$. Toftdahl Moller: Christen Kolds skole og hans ture til Sjælland. - Sorø Amtstid. 17. okt. I958.

H. S.: Ludvig Schrøder. - Højskolebl. 7. febr. 1958.

H. S.: En mindedag. F. E. Boisen, I808-82. - Højskolebl. 2 I. febr. 1958.

Jubilæumsartikler og -afhandlinger $\mathrm{i}$ anledning af roo-året for Jakob Knudsens fødsel ikke registreret i nærv. oversigt. 
q. Grundtvig-Selskabet og dets publikationer.

Gr.-Selskabet har i 1958 udsendt følgende:

Grundtvig-Studier 1958. Under redaktion af Gustav Albeck (123 s.). Anmeldt bl. a. af flg.: $R$. A. i Dansk Kirketid. 8. febr. 1959; $h$. i Frederiksborg Amts Avis 22. dec. 1958; Johan Klejs i Information 19. febr. I959; C.T. (॰: Carl Trock) i Præsteforeningens Blad 12. dec. 1958.

Registrant over N. F. S. Grundtvigs papirer. Bd. IV-IX. - Se gruppe I her foran.

Henning Høirup: Beretning om Grundtvig-Selskabets virksomhed. Gr.-Studier I958, I 20-I 22.

Grundtvig-Selskabets årsmøde. - Kr. Dagbl. 8. sept. I958. (Kortfattede oplysninger).

\section{Tilfojelser til tidligere oversigter over Grundtvig-litteratur.}

Til oversigten over litteratur 1954 (i Gr.-Studier 1956) tilfojes:

Ad IV p: Carl Dumreicher: Ved en Milepæl. Talt og skrevet. 1954. ( 136 s.). - Heri s. 8I-92: Et grundtvigsk Vidunderbarn. - (Om Anders Svendsen Hovmøller).

Til oversigten over litteratur 1955 ( $i$ Gr.-Studier 1957) tilfojes:

Ad III: Ingeborg Moller: Fra gullalderen i nordisk diktning. Oslo 1955. (248 s.). - Heri om Gr. s. 47-70.

Til oversigten over litteratur 1956 ( $i$ Gr.-Studier 1958) tilfojes:

Ad IV $b$ (ell. c): Kjeld Galster: Strid mellem Danske og Holstenere om mindesmærker for Niels Ebbesen og for Grev Gert omkring 1840. - Jyske Samlinger, ny række III (1954-56), I53-177. - Heri også om Gr. (jf. bibl. nr. 630).

Ad IV p: P. G. Lindhardt: Bisperne mellem højre og venstre. - Jyske Samlinger, ny række III ( 1954-56), I25-137. - Heri også om grundtvigianismen i Kbh. i I8goerne, jf. en avisartikel af P. G. L. om samme emne, se Gr. Stud. 1958, I18 (»Det første Bispevalg«).

P. G. Lindhardt: Kampen om det teologiske fakultet. - Jyske Samlinger, ny række III (1954-56), 217-242. Bl. a. om valg af grundtvigsk sindede professorer ved Kbh.s universitet i I87oerne, jf. en avisartikel af P. G. L. om samme emne, se Gr.-Stud. 1958, i 8 (»Kampen om det teologiske fakultet $)$.

Til oversigten over litteratur 1957 (i Gr.-Studier 1959) tilføjes:

Ad III: I »Deutsche Philologie im Aufriss «, hrsg. von Wolfgang Stammler, bd. III (1957), har prof. dr. Carl Roos skrevet afsnittet »Die nordischen Literaturen《 (sp. I-34). Heri berøres (sp. 22) Grundtvig ganske kort. I samme bind omtales Gr. også sp. I653 (i en afh. af Martin Schmidt). 
Ad IV b: J. P. Trap: Danmark ${ }^{5}$ V,2 (1957). Svendborg amt. - Heri om Egeløkke s. 946 f. - Gr. kort omtalt.

Ad IV c: Ole Vig - brev. Utg. av Torstein Hoverstad. Hamar 1957. (I27 s.).

- Kortfattet anmeldt af J.M. J. i Højskolebl. 9. maj 1958. - I disse breve også udførligt om Ole Vigs Danmarksbesøg og besøg hos Gr.

Ad IV d: Kirkeligt Samfunds årsmøde 1957. - Dansk Kirketid. 3. nov. I957.

- Heri referat af Harald Engberg Pedersens foredrag om forholdet mellem det folkelige og det kristelige, hvori også om Gr.s syn på kristendommen. - Hertil Peter Riemann: Et »Kirkens genmæle« smst. 22. dec. 1957. Hertil Jens Jensen: Har Gr. uret? Smst. I6. febr. 1958.

Ad IV f.2: Uffe Hansen: Gr.-salme optaget i den nye salmebog. - Dag. Nyh. 21. juli 1957. - Om salmen »Der sad en Fisker saa tankefuld«. Ad IV q: Gr.-Studier 1957 også anmeldt i Nord. Tidskrift 1958, I89 af Jö. ( 0 : Harald Jorgensen).

Poul Engberg: Grundtvig-Selskabet gennem io år. - Højskolebl. i7. jan. 1958. - Foranlediget af 1957-årgangen af Gr.-Studier (Høirups tilbageblik s. 7 ff.). 